TI 2011-046/3

Tinbergen Institute Discussion Paper

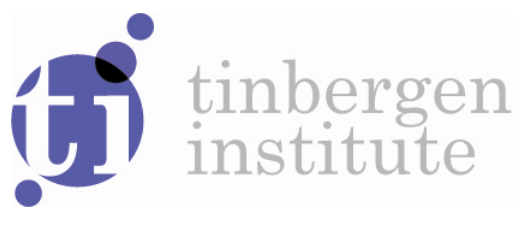

\title{
Hormones and Social Preferences
}

Thomas Buser

Amsterdam School of Economics, University of Amsterdam, and Tinbergen Institute. 
Tinbergen Institute is the graduate school and research institute in economics of Erasmus University Rotterdam, the University of Amsterdam and VU University Amsterdam.

More TI discussion papers can be downloaded at http://www.tinbergen.nl

Tinbergen Institute has two locations:

Tinbergen Institute Amsterdam

Gustav Mahlerplein 117

1082 MS Amsterdam

The Netherlands

Tel.: +31(0)205251600

Tinbergen Institute Rotterdam

Burg. Oudlaan 50

3062 PA Rotterdam

The Netherlands

Tel.: +31(0)10 4088900

Fax: +31(0)104089031

Duisenberg school of finance is a collaboration of the Dutch financial sector and universities, with the ambition to support innovative research and offer top quality academic education in core areas of finance.

DSF research papers can be downloaded at: http://www.dsf.nl/

Duisenberg school of finance

Gustav Mahlerplein 117

1082 MS Amsterdam

The Netherlands

Tel.: +31(0)20 5258579 


\title{
Hormones and social preferences
}

\author{
Thomas Buser*
}

February 2011

\begin{abstract}
We examine whether social preferences are determined by hormones. We do this by investigating whether markers for the strength of prenatal testosterone exposure (finger length ratios) and current exposure to progesterone and oxytocin (the menstrual cycle) are correlated with choices in social preference games. We find that subjects with finger ratios indicating high prenatal testosterone exposure give less in the trust, ultimatum and public good games and return a smaller proportion in the trust game. The choices of female subjects vary over the menstrual cycle according to a pattern consistent with a positive impact of oxytocin on giving in the trust and ultimatum games and a positive impact of progesterone on altruism. We find no impact for subjects taking hormonal contraceptives. We conclude that both prenatal and current exposure to hormones play an important role in shaping social preferences.
\end{abstract}

\footnotetext{
*University of Amsterdam, School of Economics (t.buser@uva.nl; buser.economists.nl). I am indebted to Hessel Oosterbeek and Erik Plug for their advice and support. I also thank Lygia Cesar for great research assistance in the lab. I gratefully acknowledge financial support from the University of Amsterdam through the Speerpunt Behavioural Economics and thank CREED for letting me use their lab.
} 


\section{Introduction}

There is a large literature showing that levels of altruism, trust and reciprocity vary strongly across people. However, we still know little about the determinants of these individual differences. In this paper, we analyse the correlation between behaviour in social preference games and markers for hormone exposure in order to examine whether these preferences are partially determined by the effects of hormones. Hormones can have permanent organisational effects as well as immediate effects and our study looks at both. ${ }^{1}$ In particular, we use the second-to-fourth digit ratio $^{2}$, which is a marker for prenatal testosterone exposure, and menstrual cycle information, which is a proxy for the current exposure to a range of hormones. We argue that a significant correlation between these markers and economic choices in social situations would suggest that hormones play a role in shaping social preferences.

The organisational effects of testosterone exposure occur between weeks seven and twelve of pregnancy and the relative strength of exposure is thought to have a crucial impact on brain development. Stronger testosterone exposure leads to a stronger lateralisation of brain functions - i.e. a decrease in the likelihood that the brain uses both sides for a given task - and a stronger development of the right hemisphere relative to the left (Grimshaw et al., 1995). The main connection between the two hemispheres of the brain is a thick band called corpus callosum which contains millions of nerves and acts as a data-wire that allows the two hemispheres to "speak" to each other. Stronger prenatal exposure to testosterone is associated with a smaller corpus callosum (Witelson and Nowakowski, 1991).

Overall, prenatal testosterone exposure is thought to shift brain development from a brain geared towards empathy in the direction of a brain wired for dealing with systems. ${ }^{3}$ This is not a dichotomy but a continuum at the extreme systems end of which lies autism, a condition characterised by extremely low levels of empathy and an obsession with systems. ${ }^{4}$ These differences are present already at birth (Lutchmaya and Baron-Cohen, 2002), and at four years of age children with higher exposure have significantly lower social skills and more restricted interests (Knickmeyer et al., 2005).

The most commonly used proxy for prenatal testosterone exposure is the second-to-fourth digit length ratio (2D:4D), the ratio of the length of the index finger to the length of the ring finger. There is a large body of evidence from the medical and behavioural sciences, surveyed in Section 2.1, showing that $2 \mathrm{D}: 4 \mathrm{D}$ is negatively correlated to prenatal testosterone exposure. The economic literature on 2D:4D has focused mainly on risk preferences and has generally found that prenatal testosterone exposure leads to lower rates of risk aversion in the lab (Dreber and Hoffman, 2007; Apicella et al.,

\footnotetext{
${ }^{1}$ Organisational effects are permanent effects of hormones on the structure and functioning of the body and brain. The critical periods during which organisational effects mostly occur are foetal development and puberty.

${ }^{2}$ The second-to-fourth digit ratio, usually referred to as $2 \mathrm{D}: 4 \mathrm{D}$, is the ratio of the length of the index finger to the length of the ring finger.

${ }^{3}$ See Baron-Cohen et al. (2004) for a review of the large body of research backing this theory.

${ }^{4}$ Manning et al. (2001) find that prenatal testosterone exposure is significantly higher in children with autism, as well as in their parents and siblings.
} 
2008). Sapienza et al. (2009) find that MBA graduates with high prenatal testosterone exposure are more likely to seek out a career in finance, while Coates et al. (2009) find that high-frequency traders with low 2D:4D have both higher profitability and lower risk aversion. There is also a small number of previous studies looking at 2D:4D and behaviour in social preference games, finding a negative correlation with rejection rates in the ultimatum game (van den Bergh and Dewitte, 2006) and giving in the dictator game (Millet and Dewitte, 2009), although the latter relationship significantly depends on context. ${ }^{5}$ Pearson and Schipper (2009b), on the other hand, find no correlation between 2D:4D and bidding or profits in first-price sealed-bid auctions.

The menstrual cycle is characterised by predictable variations in the levels of a range of hormones, including the widely studied female sex hormones oestrogen and progesterone. The behavioural impacts of progesterone include sedative and anti-anxiety effects (van Broekhoven et al., 2006). Moreover, Rode et al. (1995) find that brain functions are less lateralised during the part of the menstrual cycle when progesterone is being produced. Levels of the hormone oxytocin also fluctuate predictably over the cycle. The hormonal fluctuations over the menstrual cycle are described in detail in Section 2.2 .

The impact of the menstrual cycle on economic decision making has first been analysed in the context of first-price auctions. Chen et al. (2009) find that bidding fluctuates over the menstrual cycle for users of hormonal contraceptives only. In a replication, Pearson and Schipper (2009a) also find significant, but partially contradictory, fluctuations. Two recent papers find that competitiveness, as measured by the likelihood of entering a tournament, fluctuates strongly and significantly over the menstrual cycle. Buser (2011) finds that competitiveness - measured as the likelihood of choosing a tournament over piece-rate compensation - varies strongly over the menstrual cycle and is negatively correlated with progesterone levels (see also Wozniak et al., 2010). Randomly treating a sample of post-menopausal women with oestrogen, Zethraeus et al. (2009), on the other hand, find no impact on altruism, trust or fairness. Finally, a series of placebo controlled studies demonstrates that oxytocin induces higher offers in the trust game (Kosfeld et al., 2005; Baumgartner et al., 2008) and increases generosity in the ultimatum game (Zak et al., 2007).

A number of further studies have investigated the link between biological factors and social preferences using other approaches. Burnham (2007) detects a positive correlation between current testosterone levels and rejections in the ultimatum game and Zak et al. (2009), in a placebo controlled study, find testosterone to cause both lower offers and more rejections. Comparing the behaviour of monozygotic and dizygotic twins, a number of studies demonstrate that giving and reciprocity in the trust game (Cesarini et al., 2008), responder behaviour in the ultimatum game (Wallace et al., 2007), and generosity in the dictator game (Cesarini et al., 2009) are partly hereditary. Yet another strand of the literature has found links between specific genes and behaviour in the dictator game (Knafo et al., 2008; Israel et al., 2009). Finally, Buser (2010) finds significant correlations between left-handedness and choices in the trust, ultimatum, and dictator games.

\footnotetext{
${ }^{5}$ Exposure to aggression cues reverses the relationship.
} 
We conduct a laboratory experiment on social preferences and collect information on menstrual cycles, contraceptive use and 2D:4D through a post-experimental questionnaire. We find evidence for a negative impact of prenatal testosterone exposure on giving rates in the trust, ultimatum and public good games and some weaker evidence for a negative impact on positive reciprocity in the trust game. Giving rates in the trust game vary over the menstrual cycle according to a pattern consistent with a positive impact of oxytocin. We also find evidence for a positive impact of progesterone on giving in the dictator and ultimatum games and on reciprocity in the trust and ultimatum games.

Section 2 gives details on the markers we use to capture hormonal effects. Section 3 describes the data and Section 4 explains the experimental design. Section 5 describes the results and discusses them. Finally, Section 6 concludes.

\section{Hormonal markers}

\subsection{D:4D}

The ratio of the length of the index finger to the length of the ring finger (2D:4D), which is established in utero, has been used extensively as a marker for the strength of prenatal testosterone exposure whereby the right-hand ratio is often found to be the more accurate predictor. 2D:4D is negatively correlated with exposure - the stronger the exposure, the shorter the index finger relative to the ring finger - and is reliably higher in women. Lutchmaya et al. (2004) directly measure foetal oestrogen and testosterone levels and record digit lengths at age two. They find that the right-hand digit ratio is significantly correlated with prenatal testosterone levels as well as with the ratio of prenatal testosterone to oestrogen levels. Earlier studies show that individuals with conditions associated with very high prenatal testosterone levels exhibit significantly smaller 2D:4D (Brown et al., 2002). ${ }^{6}$

We collect 2D:4D information through a post-experimental questionnaire. We ask subjects the following questions: "On your left (right) hand, which finger is longer: the index finger or the ring finger?". We validated this measure, which can be easily included in any questionnaire, by taking hand scans from 78 undergraduate students at the University of Amsterdam and asking them the same questions. Digit lengths were measured from the crease closest to the finger to the fingertip using a photo-editing software, a method that has been previously validated by comparing it to bone measurements taken from x-rays (Manning et al., 2000). Individuals who indicated a longer index finger have significantly higher 2D:4D than individuals indicating a longer ring finger (OLS with robust standard errors and no additional controls; $p=0.000$ for the right and $p=0.004$ for the left hand). The difference in average 2D:4D between individuals indicating a longer ring finger and those indicating a longer index finger is approximately equal to one standard deviation.

\footnotetext{
${ }^{6}$ See Lutchmaya et al. (2004) for a summary of further indirect evidence for the link between testosterone and 2D:4D.

${ }^{7}$ Possible answers are "index finger", "ring finger", and "equal length".
} 
Figure 1: Hormone Levels over the Menstrual Cycle

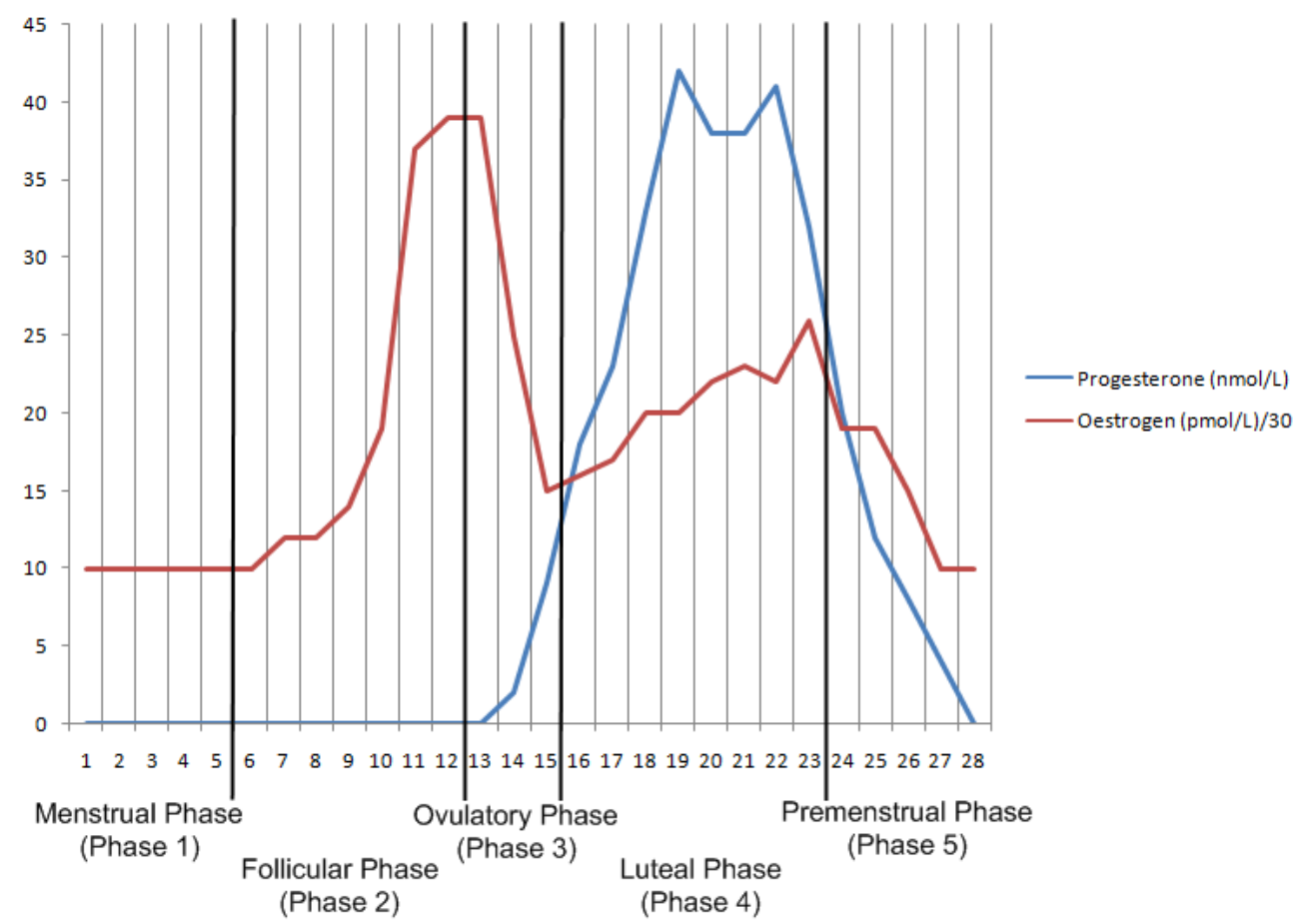

Hormone levels are obtained from Chabbert Buffet et al. (1998); oestrogen levels have been reduced by a factor of thirty.

We expect lower empathy to go hand in hand with lower altruism and trust. The Baron-Cohen theory posits a negative impact of prenatal testosterone exposure on empathy and we hypothesise therefore that subjects with lower 2D:4D (subjects whose ring fingers are longer than their index fingers) exhibit lower giving rates in all games. However, it is important to note that the effects of prenatal testosterone exposure need not be linear. Outcomes that are positively correlated with testosterone exposure at low levels may be negatively correlated at more elevated levels and vice versa. This has been found to be the case, for example, with respect to the impact of prenatal testosterone on homosexuality in men (Robinson and Manning, 2000).

\subsection{The menstrual cycle}

The medical literature commonly divides the menstrual cycle into five phases across which the levels of female sex hormones fluctuate according to a predictable pattern (see e.g. Richardson, 1992). ${ }^{8}$ These phases and the fluctuations of oestrogen and progesterone assuming a regular 28-day menstrual cycle are illustrated in Figure 1. Concentrations of the hormone oxytocin have also been shown to vary over the menstrual cycle: Salonia et al. (2005) show that blood levels are lower during the luteal phase than during both the follicular and ovulatory phases and Altemus et al. (2001) find that levels during the menstrual phase are equal to the low levels observed during the luteal phase.

We allocate subjects experiencing a natural menstrual cycle to one of the five menstrual cycle phases

\footnotetext{
${ }^{8}$ Levels of testosterone are virtually constant over the cycle.
} 
based on the cycle information collected through our post-experimental questionnaire. We solicited detailed menstrual cycle information including the beginning of the last menstruation, average cycle length, average length of menstruation, current menstrual bleeding and regularity of the cycle. Most of the variability in cycle length between individuals stems from differences in the length of the follicular phase. The length of the ovulatory, luteal, and premenstrual phases on the other hand is similar across individuals (Hampson and Young, 2008). We therefore adjust the length of the follicular phase to account for differences in cycle length between subjects. We further reduce misallocations by only allocating subjects to the menstrual phase who indicate to be currently experiencing menstrual bleeding.

Using self-reported menstrual cycle data nevertheless introduces measurement error. Women often misestimate their cycle length (Small et al., 2007) and cycle length tends to vary around the mean over time (Creinin et al., 2004). Moreover, while the follicular phase varies most with the length of the cycle, there is some variability in the length of other phases too (Stern and McClintock, 1998). As women estimate their cycle length correctly on average (Creinin et al., 2004), this leads to classical measurement error, introducing random noise which biases any of the estimated effects towards zero.

From the literature on the impact of oxytocin on trust we derive the hypothesis that first movers in the trust and ultimatum games send higher amounts during the follicular and ovulatory phases than during the rest of the cycle. The medical literature shows progesterone to have a calming effect and the results of Buser (2011) suggest that it leads to lower levels of competitiveness. Assuming that competitiveness is associated with lower levels of caring for the outcomes of others, we derive the hypothesis that giving rates are higher during the luteal phase than during the rest of the cycle.

\subsection{Hormonal contraceptives}

In women using hormonal contraceptives such as the pill, vaginal rings or contraceptive patches, which contain varying levels of artificial oestrogen and progestins ${ }^{9}$, hormonal fluctuations are different. These contraceptives have in common that they are subject to a 28-day cycle wherein a 21-day intake period, which is characterised by constant daily hormone doses, is followed by a 7-day break during which hormone intake levels drop to zero. Oestrogen excretion by the body is markedly reduced in women taking hormonal contraceptives and progesterone excretion ceases almost completely (Rivera et al., 1999). This leads to a regular pattern whereby levels of artificial oestrogen and progestin are high during the 21-day intake period and low during the 7-day pill break. Oxytocin levels do not vary over the cycle for contraceptive takers (Salonia et al., 2005).

We use our post-experimental questionnaire to ask a series of detailed questions concerning the use of hormonal contraceptives, including the kind of contraceptive, the number of days into the current pill packet or the current pill-break ${ }^{10}$, and whether they regularly skip pill-breaks - and therefore men-

\footnotetext{
${ }^{9} \mathrm{~A}$ progestin is a synthetic hormone that has effects similar to progesterone.

${ }^{10} \mathrm{~A}$ small number of subjects stated using hormonal contraceptive rings which are placed in the vagina for 21 days
} 
Table 1: Hypotheses

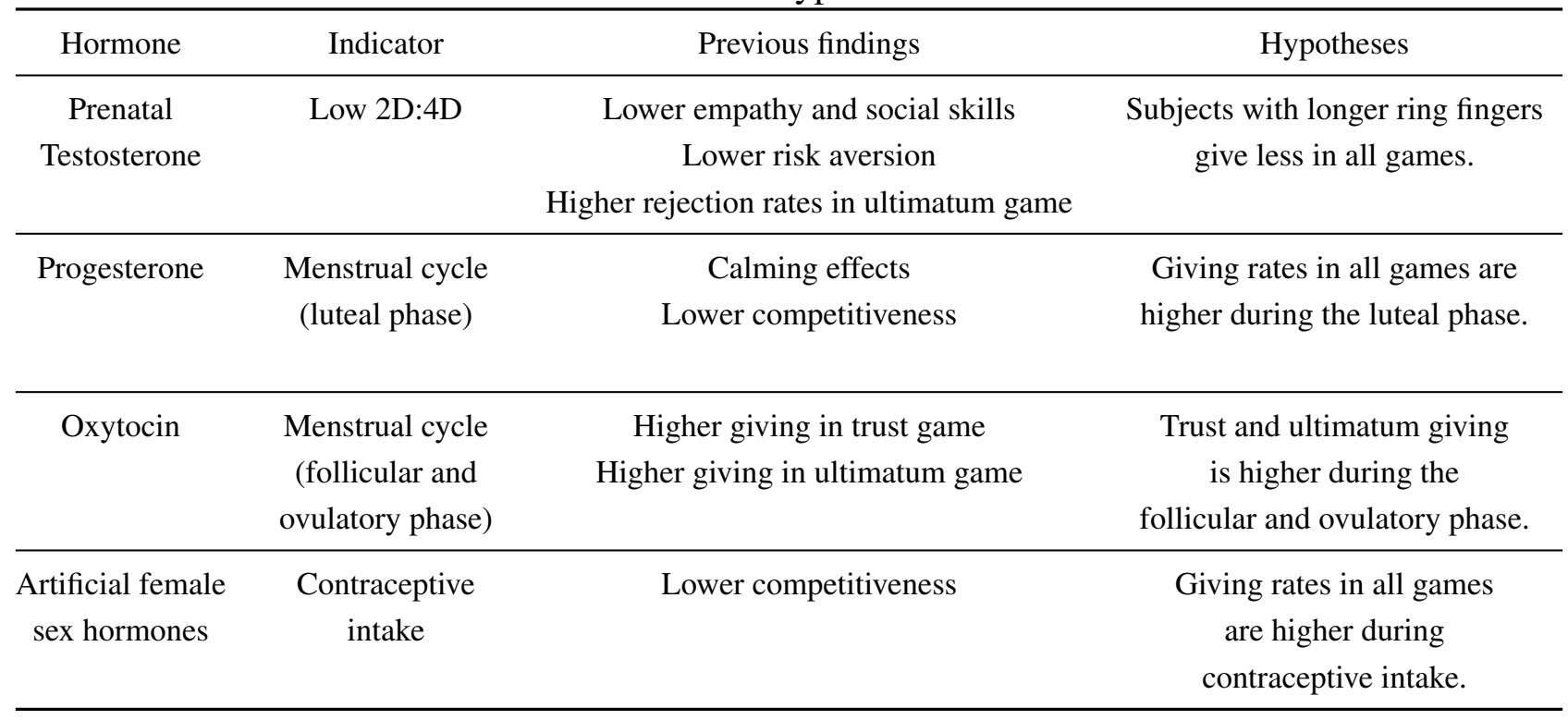

strual bleeding - by immediately starting the next packet. This allows us to construct a binary variable indicating whether a subject currently has high or low hormone levels. Buser (2011) finds hormonal contraceptives to have a negative impact on competitiveness and, in accordance with our hypotheses concerning the effects of the menstrual cycle, we hypothesise a positive effect of contraceptives on giving rates. Our hypotheses are summarised in Table 1.

\section{Data}

Table 5 in the appendix contains descriptive statistics. As expected, men are significantly more likely to indicate a longer ring finger on both hands (Wilcoxon rank-sum test; $p=0.010$ ) while women are significantly more likely to indicate a longer index finger $(p=0.001) .{ }^{11}$ Table 6 in the appendix shows the sample distribution of digit lengths. 99 subjects have a longer ring finger and 78 have a longer index finger on both hands, with the remaining 85 subjects having mixed ratios.

Table 7 in the appendix shows the distribution of female subjects across menstrual cycle phases. Five subjects indicated using implanted contraceptive devices (IUD) which completely suppress menstruation and are therefore excluded from the analysis based on cycle phases. Of the remaining 152 female subjects, 81 do not take hormonal contraceptives and therefore experience a natural cycle. When including subjects whose cycle length is irregular, menstrual phase and follicular phase subjects seem overrepresented. As mentioned above, the follicular phase is the most variable in length and our algorithm therefore adjusts the length of the follicular phase accordingly. Women who experience an followed by a break of 7 days. We asked those subjects how many days ago they applied the ring they are currently using or how many days they are into the current break.

${ }^{11}$ This also applies to the right and left hand separately. Gender difference $p$-values for ring and index finger lengths are 0.018 and 0.007 respectively for the right hand and 0.001 and 0.001 respectively for the left hand. 
irregular cycle - and whose average cycle length is therefore a bad predictor of the current cycle report cycles that are 3.9 days longer on average $(p=0.000)$ and are therefore more likely to be allocated to the follicular phase. Also, irregularly cycling women may experience intermittent menstrual bleeding and be falsely assigned to the menstrual phase. Indeed we find that 20 out of 29 irregularly cycling women are assigned to phase 1 or 2 . To make sure our results are robust, we conduct all our analyses on the subsample of regularly cycling women as well. ${ }^{12}$

\section{Experimental design}

The experiment consists of a range of standard social preference games which have been widely used in the literature: a trust game, an ultimatum game, a public good game, and a dictator game. Overall, the experiment lasted for seven rounds and subjects were randomly and anonymously rematched in each round. One of the rounds was randomly picked for payment at the end of the experiment. Subjects also received a show-up fee of $€ 10$. We ran a total of twelve sessions in December 2009 and January 2010, all of which were conducted in the computer laboratory of the Center for Research in Experimental Economics and Political Decision-Making (CREED) at the University of Amsterdam. The experiment was programmed and conducted with the software z-Tree (Fischbacher, 2007). The sessions lasted for approximately two hours and average earnings were around $€ 21$. The data from this experiment has also been used by Buser (2010).

In the trust game (Berg et al., 1995), two subjects are paired up and each receives an endowment of $€ 10$. The first mover (the "Proposer") can then decide how much of his endowment he wishes to send to the second mover (the "Responder"). The amount sent is tripled and the Responder can then decide how much of the money, including his endowment, to send back to the Proposer. Because the Responder has no financial incentive to send back anything, the subgame-perfect Nash equilibrium predicts that the Proposer will not send any money. In the social optimum, on the other hand, the Proposer would send his entire endowment of $€ 10$ and the Responder would return less than $€ 30$ and more than $€ 10$, leaving both parties better off. There is a large literature showing that Proposers send on average around 50 percent of their endowment and that Responders reciprocate by returning on average nearly 50 percent of the received transfer (Levitt and List, 2007). In our experiment, we implemented two rounds of the trust game with each subject taking each role once.

In the ultimatum game (Güth et al., 1982), the Proposer receives an endowment of $€ 20$ while the Responder starts out with nothing. The Proposer decides how much to send to the Responder who can then decide whether to accept or reject the proposal. In case of rejection, both players receive zero, so that the subgame-perfect Nash equilibrium predicts that all positive offers are accepted and Proposers should thus send the lowest possible amount. Again, there is a large literature showing that

\footnotetext{
${ }^{12}$ Menstrual cycle details are sensitive information to ask and a female assistant was therefore present at all sessions and was responsible for all interactions with the subjects concerning the post-experimental questionnaire. In the end, selective non-response turned out not to be a problem as all subjects chose to answer the questions.
} 
Proposers send positive amounts, usually in the range between 25 and 50 percent of their endowment, and that Responders are willing to forfeit money by rejecting low offers (Roth, 1995). Again, there were two rounds with each subject fulfilling each role once.

The public good game is a generalisation of the prisoner's dilemma game whereby subjects are matched in groups of four and are each endowed with $€ 15$. They can then decide how much of the endowment to keep and how much to give to the group. Each Euro given to the group is doubled and split equally amongst the group members such that each Euro given to the group pays 50 Cents to each group member. The social optimum is for all the players to invest everything, but as each player has an incentive to free-ride, the Nash equilibrium predicts zero contributions. There is a large literature reporting substantial positive contributions, usually around 50 percent of the initial endowment in a one-shot setting (Ledyard, 1995).

Finally, we implemented a binary version of the dictator game (Kahneman et al., 1986). In the dictator game, the Proposer again receives an endowment of $€ 20$ and has to pick between two options: splitting the pot equally with the Responder (who receives no endowment) or keeping $€ 18$ while giving only $€ 2$ to the Responder. The Responder has no possibility to reciprocate and the game is consequently a good tool for measuring altruism. The Nash equilibrium of course predicts that the Proposer sends the smallest amount possible, but a large literature finds that when able to decide freely, over 60 percent of subjects send a positive amount (Roth, 1995). Again, subjects play each role once.

\section{Results}

\subsection{D:4D}

The regression results in Table 2 show differences between subjects who have a longer ring finger on both hands and the rest of the sample. As both ratios are predictors of exposure levels, these subjects in expectation are the group with the highest prenatal exposure to testosterone. ${ }^{13}$ Table 8 in the appendix shows results using other digit ratio indicators. In both tables, the dependent variables are the initial offer and the proportion returned in the trust game in Columns 1 and 2, the initial offer in the ultimatum game and a rejection dummy for ultimatum responders in Columns 3 and 4, the contribution to the public good and a binary variable indicating whether the contribution was larger than zero in Columns 5 and 6, and a binary indicator for choosing the selfish allocation in the dictator game in Column 7. All regressions control for gender to avoid that the finger ratio coefficients simply pick up gender effects. Additionally, we control for age and nationality in all regressions. ${ }^{14}$ The

\footnotetext{
${ }^{13}$ Because the left-hand ratio is a noisier predictor, however, taking the double ratio leads to more measurement error than taking the right-hand ratio only. Having a longer ring finger on both hands is more restrictive than having a longer finger only on the right hand and the errors made when going from using right-hand finger ratios to double ratios therefore only go in one direction: some high exposure subjects will be associated to the middle group and consequently bias the finger ratio coefficient downwards, weakening the power to detect a difference.

${ }^{14}$ Results without controls are very similar and are therefore not reported.
} 
regressions in Columns 2 and 4, which deal with responder behaviour, also control for the amount received from the proposer. Table 3 summarises the results from the regressions reported in Tables 2 and 8.

Table 2: Relative length of ring finger (double 4D) and social preferences

\begin{tabular}{|c|c|c|c|c|c|c|c|}
\hline & $\begin{array}{l}\text { (1) } \\
\text { Trust }\end{array}$ & $\begin{array}{c}(2) \\
\text { Proportion }\end{array}$ & $\begin{array}{c}(3) \\
\text { Ultimatum }\end{array}$ & $\begin{array}{c}(4) \\
\text { Rejection }\end{array}$ & $\begin{array}{c}\text { (5) } \\
\text { Public Good }\end{array}$ & $\begin{array}{c}\text { (6) } \\
\text { PG Positive }\end{array}$ & $\begin{array}{c}(7) \\
\text { Selfish }\end{array}$ \\
\hline $\begin{array}{l}\text { Longer ring } \\
\text { (left and right) }\end{array}$ & $\begin{array}{c}-1.015^{* * * *} \\
(0.385)\end{array}$ & $\begin{array}{c}-0.01 \\
(0.015)\end{array}$ & $\begin{array}{c}-0.960^{* *} \\
(0.401)\end{array}$ & $\begin{array}{c}0.021 \\
(0.041)\end{array}$ & $\begin{array}{l}-0.789 \\
(0.647)\end{array}$ & $\begin{array}{c}-0.121^{* *} \\
(0.056)\end{array}$ & $\begin{array}{c}0.039 \\
(0.040)\end{array}$ \\
\hline $\mathrm{N}$ & 252 & 252 & 252 & 252 & 252 & 252 & 252 \\
\hline $\begin{array}{l}\text { Mean } \\
\text { SD }\end{array}$ & $\begin{array}{c}4.020 \\
(3.076)\end{array}$ & $\begin{array}{c}0.121 \\
(0.141)\end{array}$ & $\begin{array}{c}7.992 \\
(3.180)\end{array}$ & $\begin{array}{c}0.127 \\
(0.334)\end{array}$ & $\begin{array}{c}6.242 \\
(4.825)\end{array}$ & $\begin{array}{c}0.774 \\
(0.419)\end{array}$ & $\begin{array}{c}0.881 \\
(0.325)\end{array}$ \\
\hline Controls & yes & yes & yes & yes & yes & yes & yes \\
\hline Offer received & no & yes & no & yes & no & no & no \\
\hline Scale & $0-10$ & $0-1$ & $0-20$ & binary & $0-15$ & binary & binary \\
\hline
\end{tabular}

Our hypothesis of a positive correlation between 2D:4D and giving rates is not rejected for any of the games. Table 2 shows that subjects with a longer ring finger on both hands give significantly less than the rest of the sample in both the trust and the ultimatum game. These effects are sizeable and amount to a reduction in giving rates of 25.2 percent in the trust game and 12.0 percent in the ultimatum game compared to the mean. The same subjects are also significantly less likely to offer positive amounts in the public good game (a reduction of 12.1 percentage points compared to a mean of 77.4 percent). Table 3 shows that when using the right hand ratio only, subjects with a longer ring finger also return a significantly lower proportion in the trust game (a reduction of 2.9 percentage points compared to a mean of 12.1 percent) and contribute 16.9 percent less in the public good game. Rejection rates in the ultimatum game and the likelihood of choosing the generous allocation in the dictator game are never significantly affected, although the coefficients have the expected sign. ${ }^{15}$

\footnotetext{
${ }^{15}$ The ring finger coefficient for ultimatum rejections is positive, if not significant, which is in accordance with van den Bergh and Dewitte (2006) who find that 2D:4D is significantly and negatively correlated with rejection rates.
} 
Table 3: Finger ratios (2D:4D) and social preferences: summary of regressions

(1)

\begin{tabular}{|c|c|c|c|c|}
\hline & & Right hand & Left hand & Double \\
\hline \multirow[t]{2}{*}{ Trust } & $4 \mathrm{D}$ & $-* *$ & $-* *$ & -*** \\
\hline & 2D:4D & $-*$ & $-* *$ & $-* *$ \\
\hline \multirow[t]{2}{*}{ Proportion } & $4 \mathrm{D}$ & $-* *$ & - & - \\
\hline & 2D:4D & $\sim^{*}$ & $\sim$ & - \\
\hline \multirow[t]{2}{*}{ Ultimatum } & $4 \mathrm{D}$ & - & $-* * *$ & $-* *$ \\
\hline & 2D:4D & $\sim$ & $-* *$ & $-*$ \\
\hline \multirow[t]{2}{*}{ Reject } & $4 \mathrm{D}$ & + & + & + \\
\hline & 2D:4D & $\sim$ & $\sim$ & + \\
\hline \multirow[t]{2}{*}{ Public Good } & $4 \mathrm{D}$ & $-*$ & - & - \\
\hline & 2D:4D & $\sim * *$ & $\sim$ & $\sim$ \\
\hline \multirow[t]{2}{*}{ PG positive } & $4 \mathrm{D}$ & $-* *$ & - & $-* *$ \\
\hline & 2D:4D & $\sim * * *$ & $\sim$ & $\sim *$ \\
\hline \multirow[t]{2}{*}{ Selfish } & $4 \mathrm{D}$ & + & + & + \\
\hline & 2D:4D & + & $\sim$ & $\sim$ \\
\hline
\end{tabular}

When splitting the sample into three groups by also adding an index finger dummy, most of the results are unaffected - i.e. those with longer ring fingers are less generous than the middle group and those with longer index fingers are more generous. But for the public good game we obtain nonlinear effects: both subjects with longer ring fingers and subjects with longer index fingers are less generous than the middle group. This is consistent with the findings of Sanchez-Pages and Turiegano (2010) who find that individuals with intermediate values of 2D:4D are more likely to cooperate in a prisoner's dilemma game than either low or high 2D:4D subjects.

\subsection{Menstrual cycle}

The graphs in Figure 2 show choices for female subjects in different phases of their menstrual cycle relative to the average choice of male subjects. Table 9 in the appendix reports coefficients for regressions including controls for age and nationality and for regressions using only regularly cycling subjects. It is important to note that most of the effects are robust to restricting the sample to regular cyclers.

Women give significantly less than men in the trust game during the menstrual and pre-menstrual phases, but not during the middle part of their cycle. We hypothesised that trust would move in step 
with oxytocin levels and therefore be higher during the follicular and ovulatory phases than during the rest of the cycle. This is confirmed by the data as subjects in these cycle phases give 1.84 Euros more than subjects in the rest of the cycle (OLS regression; $p=0.004$ and $p=0.017$ without and with controls respectively).

We hypothesised that giving in all games should be higher during the luteal phase than during the rest of the cycle. This effect is observed for the dictator game where women are significantly more likely than men to pick the equal allocation in the luteal phase only. These women are more than 20 percentage points more likely to pick the equal allocation than women in other cycle phases, a large difference compared to a sample mean of 11.9 percent (this difference is significant when restricting the sample to regular cyclers; OLS regression; $p=0.066$ ). Responders in the trust game are in a situation which is very similar to being a first mover in a dictator game and, conditional on the amount received from the first mover, higher altruism should therefore lead to a higher proportion returned. Indeed, women return a higher proportion than men during the luteal phase only, returning almost twice as much than during the rest of the cycle. The difference between the luteal phase and the rest of the cycle is also significant ( $p=0.033$ and $p=0.036$ without and with controls respectively).

Giving rates in the ultimatum game do not vary significantly over the cycle but we do observe a midcycle peak consistent with a positive impact of oxytocin on ultimatum giving. Female responders are significantly less likely than their male counterparts to reject the amount offered during the ovulatory and luteal phases, but the difference between the luteal phase and the rest of the cycle is not significant (OLS regression; $p=0.127$ ). Finally, contributions in the public good game do not vary significantly over the cycle although women are more likely than men to make a positive contribution during all cycle phases.

To confirm the impacts of progesterone indicated by the cycle phase results and to test for potential impacts of oestrogen, in Table 10 in the appendix we regress choices in the social preference games on expected hormone levels given the estimated cycle day. ${ }^{16}$ Giving in the dictator and ultimatum games, as well as reciprocity in the trust game are significantly positively correlated with progesterone levels which is consistent with a positive impact of progesterone on altruism. More surprisingly, the likelihood of rejection in the ultimatum game is also positively correlated with progesterone levels (this effect is significant when restricting the sample to regular cyclers). The effect of fluctuations in oestrogen levels is never significant. ${ }^{17}$

It is difficult to say what these menstrual cycle results predict for contraceptive takers. Many studies which find significant fluctuations over the natural menstrual cycle find no effect for contraceptive takers. ${ }^{18}$ Moreover, the artificial hormones contained in hormonal contraceptives are not identical to

\footnotetext{
${ }^{16}$ The expected hormone levels are taken from Chabbert Buffet et al. (1998). We did not take any direct hormone measurements.

${ }^{17}$ We could not find any study reporting average oxytocin levels over the menstrual cycle at a daily level and can therefore not conduct a similar analysis for the effects of oxytocin.

${ }^{18}$ See Bröder and Hohmann (2003) on risky behaviour, Penton-Voak et al. (1999) on preferences for male faces, Thornhill and Gangestad (1999) on preferences for male body odour, and Miller et al. (2007) on tips earned by lap dancers.
} 
Figure 2: The menstrual cycle and social preferences
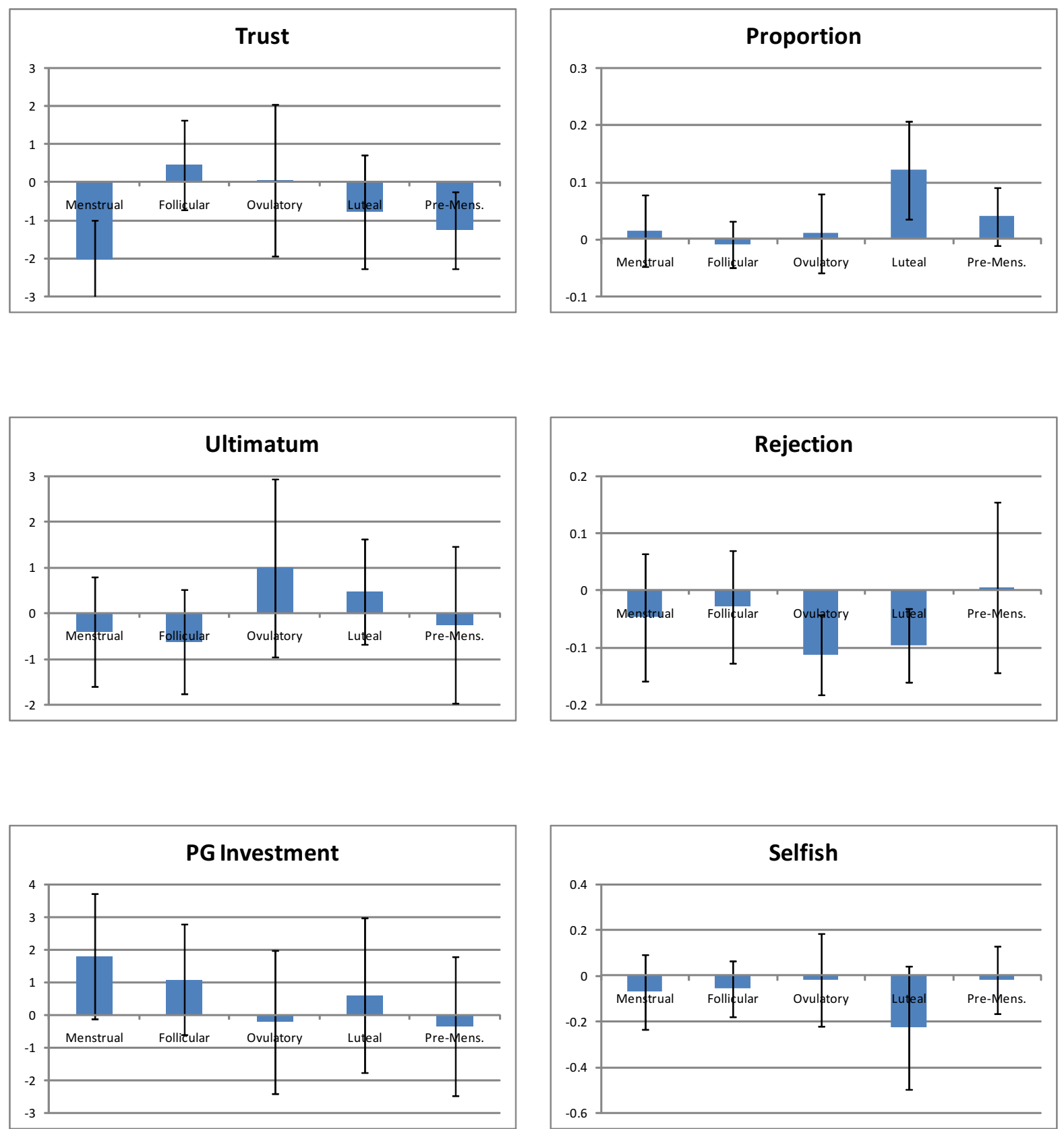

Coefficients and 90\%-confidence intervals are from OLS regressions; the regressions on trust and ultimatum game reciprocity control for amounts received; effects are shown relative to the average choices of male subjects. 
Table 4: Hormonal contraceptives and social preferences

\begin{tabular}{|c|c|c|c|c|c|c|c|}
\hline & $\begin{array}{l}\text { (1) } \\
\text { Trust }\end{array}$ & $\begin{array}{c}(2) \\
\text { Proportion }\end{array}$ & $\begin{array}{c}\text { (3) } \\
\text { Ultimatum }\end{array}$ & $\begin{array}{c}(4) \\
\text { Rejection }\end{array}$ & $\begin{array}{l}(5) \\
\text { PG }\end{array}$ & $\begin{array}{c}(6) \\
P G>0\end{array}$ & $\begin{array}{c}(7) \\
\text { Selfish }\end{array}$ \\
\hline Pill Break & $\begin{array}{c}0.008 \\
(0.770)\end{array}$ & $\begin{array}{l}-0.024 \\
(0.023)\end{array}$ & $\begin{array}{c}0.183 \\
(1.057)\end{array}$ & $\begin{array}{l}-0.041 \\
(0.097)\end{array}$ & $\begin{array}{c}0.070 \\
(1.271)\end{array}$ & $\begin{array}{l}-0.040 \\
(0.111)\end{array}$ & $\begin{array}{l}-0.010 \\
(0.075)\end{array}$ \\
\hline $\mathrm{N}$ & 71 & 71 & 71 & 71 & 71 & 71 & 71 \\
\hline Mean & 3.647 & 0.117 & 8.845 & 0.197 & 6.197 & 0.817 & 0.915 \\
\hline SD & 2.747 & 0.134 & 3.500 & 0.401 & 4.496 & 0.390 & 0.280 \\
\hline Controls & yes & yes & yes & yes & yes & yes & yes \\
\hline Offer received & no & yes & no & yes & no & no & no \\
\hline Scale & $0-10$ & $0-1$ & $0-20$ & binary & $0-15$ & binary & binary \\
\hline
\end{tabular}

Robust standard errors in parentheses; ${ }^{* * *} \mathrm{p}<0.01,{ }^{* *} \mathrm{p}<0.05,{ }^{*} \mathrm{p}<0.1$; controls consist of gender, age and nationality; the sample is restricted to contraceptive takers.

their natural counterparts oestrogen and progesterone. Each pill brand contains a different artificial progestin, some of which, apart from imitating the effects of natural progesterone, also have a list of strong side effects (Mansour, 2006). But Buser (2011) finds that the effects of hormonal contraceptives on competitiveness are consistent with the difference between the high progesterone luteal phase and the rest of the cycle. Following the results from the previous section, we therefore expected subjects on the pill break, when hormone levels are low, to be less generous than subjects currently under the influence of contraceptives. The regressions reported in Table 4 show that this is not the case. For none of the social preference games are the choices of subjects in the pill-break different from the choices of subjects who were taking contraceptives at the time of the experiment.

\section{Conclusions}

We interpret our findings as providing evidence that individual differences in trust, reciprocity and altruism are partially biologically determined. Subjects who have been more strongly exposed to testosterone in utero are less trusting and less altruistic. As prenatal testosterone exposure has important organisational effects on the brain, this is evidence for a neural basis for social preferences. In particular, it raises the possibility that social preferences are linked to the thickness of the corpus callosum. The extent to which brain functions are lateralised and the extent to which an individual's brain is capable of efficiently communicating between the hemispheres seem to have an important impact on decision making in social situations.

For women who experience a natural menstrual cycle, giving in the trust game moves in step with expected changes in oxytocin levels. This shows for the first time that the positive impact of oxytocin on trust, which has been demonstrated in placebo controlled experiments, is present for natural fluctuations as well. We also find evidence that altruism increases during the part of the menstrual cycle 
when progesterone levels are high. This effect of progesterone on altruism is confirmed by regressions using daily expected progesterone levels. These results suggest that current levels of progesterone and oxytocin have a significant impact on economic choices in social situations.

The hormonal markers we use are imprecise devices but they have unique advantages. Our 2D:4D indicators are simple enough to be included in questionnaires which is impossible for hand-scans and hormone assays, let alone for direct prenatal hormone measurements during pregnancy. Furthermore - contrary to exogenously induced hormone shocks - the menstrual cycle occurs naturally and constantly, making the estimated effects especially relevant as predictors of choices in social situations. Our results fit well with the growing literature showing that the strong individual differences observed in a huge number of social preference experiments are at least partially biologically determined. 


\section{Appendix}

Table 5: Lab sample characteristics

\begin{tabular}{lcccc}
\hline & Sample & Women & Men & Gender-dif. P-val. \\
\hline $\mathrm{N}$ & 252 & 157 & 95 & \\
2x ring finger longer & 99 & 52 & 47 & 0.010 \\
2x index finger longer & 78 & 60 & 18 & 0.001 \\
Age & 22.13 & 22.02 & 22.32 & \\
Nationality (in \%) & & & & \\
Dutch & 71.83 & 68.79 & 76.84 & \\
Western Europe & 3.97 & 4.46 & 3.16 & \\
Eastern Europe & 11.90 & 13.38 & 9.47 & \\
Asia & 8.73 & 11.46 & 4.21 & \\
America & 2.38 & 1.91 & 3.16 & \\
Other & 1.19 & 0 & 3.16 & \\
\hline
\end{tabular}

Gender-difference P-values are from Wilcoxon rank-sum tests

Table 6: Digit ratio distribution

\begin{tabular}{l|ccc|c} 
& Right 2D:4D & & Longer ring & Total \\
\hline Left 2D:4D & Longer index & Equal length & 12 & 97 \\
Longer index & 78 & 7 & 8 & 34 \\
Equal Length & 9 & 17 & 99 & 121 \\
Longer ring & 9 & 13 & 119 & 252
\end{tabular}

Table 7: Subjects by menstrual cycle phase

Menstrual Cycle or Pill Cycle Phase All subjects

Regular cyclers

\begin{tabular}{lcc} 
Menstrual Phase & 17 & 10 \\
Follicular Phase & 31 & 17 \\
Ovulatory Phase & 8 & 6 \\
Luteal Phase & 9 & 8 \\
Premenstrual Phase & 16 & 10 \\
\hline Total & 81 & 51
\end{tabular}

Pill Break (7 days) $\quad 24$

Pill Intake Phase (21 days) $\quad 47$

Total 71 
Table 8: Additional digit ratio regressions

\begin{tabular}{|c|c|c|c|c|c|c|c|}
\hline & $\begin{array}{c}(1) \\
\text { Trust }\end{array}$ & $\begin{array}{c}(2) \\
\text { Proportion }\end{array}$ & $\begin{array}{c}\text { (3) } \\
\text { Ultimatum }\end{array}$ & $\begin{array}{c}\text { (4) } \\
\text { Rejection }\end{array}$ & $\begin{array}{c}(5) \\
\text { Public Good }\end{array}$ & $\begin{array}{c}(6) \\
\text { PG Positive }\end{array}$ & $\begin{array}{c}(7) \\
\text { Selfish }\end{array}$ \\
\hline $\begin{array}{l}\text { Longer ring } \\
\text { (right) }\end{array}$ & $\begin{array}{c}-0.787 * * \\
(0.377)\end{array}$ & $\begin{array}{c}-0.029 * * \\
(0.015)\end{array}$ & $\begin{array}{l}-0.638 \\
(0.400)\end{array}$ & $\begin{array}{c}0.033 \\
(0.040)\end{array}$ & $\begin{array}{c}-1.057 * \\
(0.611)\end{array}$ & $\begin{array}{c}-0.124 * * \\
(0.053)\end{array}$ & $\begin{array}{c}0.061 \\
(0.041)\end{array}$ \\
\hline $\begin{array}{l}\text { Longer ring } \\
\text { (left) }\end{array}$ & $\begin{array}{c}-0.875 * * \\
(0.382)\end{array}$ & $\begin{array}{l}-0.021 \\
(0.015)\end{array}$ & $\begin{array}{c}-1.024 * * * \\
(0.396)\end{array}$ & $\begin{array}{c}0.011 \\
(0.040)\end{array}$ & $\begin{array}{l}-0.332 \\
(0.626)\end{array}$ & $\begin{array}{l}-0.080 \\
(0.052)\end{array}$ & $\begin{array}{c}0.005 \\
(0.041)\end{array}$ \\
\hline $\begin{array}{l}\text { Longer index } \\
\text { (left and right) }\end{array}$ & $\begin{array}{c}0.252 \\
(0.481)\end{array}$ & $\begin{array}{c}0.008 \\
(0.020)\end{array}$ & $\begin{array}{c}0.046 \\
(0.548)\end{array}$ & $\begin{array}{c}0.003 \\
(0.050)\end{array}$ & $\begin{array}{l}-0.379 \\
(0.728)\end{array}$ & $\begin{array}{l}-0.049 \\
(0.061)\end{array}$ & $\begin{array}{c}0.012 \\
(0.056)\end{array}$ \\
\hline $\begin{array}{l}\text { Longer ring } \\
\text { (left and right) }\end{array}$ & $\begin{array}{l}-0.891 * \\
(0.457)\end{array}$ & $\begin{array}{l}-0.0126 \\
(0.018)\end{array}$ & $\begin{array}{c}-0.937 * * \\
(0.460)\end{array}$ & $\begin{array}{c}0.022 \\
(0.047)\end{array}$ & $\begin{array}{l}-0.977 \\
(0.760)\end{array}$ & $\begin{array}{c}-0.145^{* *} \\
(0.063)\end{array}$ & $\begin{array}{c}0.045 \\
(0.050)\end{array}$ \\
\hline $\begin{array}{l}\text { Longer index } \\
\text { (right) }\end{array}$ & $\begin{array}{l}-0.054 \\
(0.549)\end{array}$ & $\begin{array}{l}-0.020 \\
(0.021)\end{array}$ & $\begin{array}{l}-0.344 \\
(0.590)\end{array}$ & $\begin{array}{c}0.022 \\
(0.058)\end{array}$ & $\begin{array}{l}-1.524^{*} \\
(0.812)\end{array}$ & $\begin{array}{c}-0.125^{* *} \\
(0.059)\end{array}$ & $\begin{array}{c}0.009 \\
(0.073)\end{array}$ \\
\hline $\begin{array}{l}\text { Longer ring } \\
\text { (right) }\end{array}$ & $\begin{array}{l}-0.825 \\
(0.546)\end{array}$ & $\begin{array}{c}-0.044 * * \\
(0.019)\end{array}$ & $\begin{array}{l}-0.884 \\
(0.541)\end{array}$ & $\begin{array}{c}0.049 \\
(0.057)\end{array}$ & $\begin{array}{c}-2.145^{* *} \\
(0.830)\end{array}$ & $\begin{array}{c}-0.214 * * * \\
(0.061)\end{array}$ & $\begin{array}{c}0.068 \\
(0.069)\end{array}$ \\
\hline $\begin{array}{l}\text { Longer index } \\
\text { (left) } \\
\text { Longer ring } \\
\text { (left) }\end{array}$ & $\begin{array}{c}0.546 \\
(0.558) \\
-0.479 \\
(0.548)\end{array}$ & $\begin{array}{c}-0.014 \\
(0.025) \\
-0.031 \\
(0.024)\end{array}$ & $\begin{array}{c}0.477 \\
(0.647) \\
-0.679 \\
(0.592)\end{array}$ & $\begin{array}{c}0.069 \\
(0.054) \\
0.061 \\
(0.052)\end{array}$ & $\begin{array}{c}-0.303 \\
(0.941) \\
-0.552 \\
(0.959)\end{array}$ & $\begin{array}{c}-0.035 \\
(0.078) \\
-0.105 \\
(0.078)\end{array}$ & $\begin{array}{l}-0.017 \\
(0.064) \\
-0.007 \\
(0.060)\end{array}$ \\
\hline $\begin{array}{l}\mathrm{N} \\
\text { Mean } \\
\mathrm{SD}\end{array}$ & $\begin{array}{c}252 \\
4.020 \\
(3.076)\end{array}$ & $\begin{array}{c}252 \\
0.121 \\
(0.141)\end{array}$ & $\begin{array}{c}252 \\
7.992 \\
(3.180)\end{array}$ & $\begin{array}{c}252 \\
0.127 \\
(0.334)\end{array}$ & $\begin{array}{c}252 \\
6.242 \\
(4.825)\end{array}$ & $\begin{array}{c}252 \\
0.774 \\
(0.419)\end{array}$ & $\begin{array}{c}252 \\
0.881 \\
(0.325)\end{array}$ \\
\hline Controls & yes & yes & yes & yes & yes & yes & yes \\
\hline $\begin{array}{l}\text { Offer received } \\
\text { Scale }\end{array}$ & $\begin{array}{c}\text { no } \\
0-10\end{array}$ & $\begin{array}{l}\text { yes } \\
0-1\end{array}$ & $\begin{array}{c}\text { no } \\
0-20\end{array}$ & $\begin{array}{c}\text { yes } \\
\text { binary }\end{array}$ & $\begin{array}{c}\text { no } \\
0-15\end{array}$ & $\begin{array}{c}\text { no } \\
\text { binary }\end{array}$ & $\begin{array}{c}\text { no } \\
\text { binary }\end{array}$ \\
\hline
\end{tabular}

Robust standard errors in parentheses; $* * * \mathrm{p}<0.01, * * \mathrm{p}<0.05, * \mathrm{p}<0.1$; controls consist of gender, age and nationality 


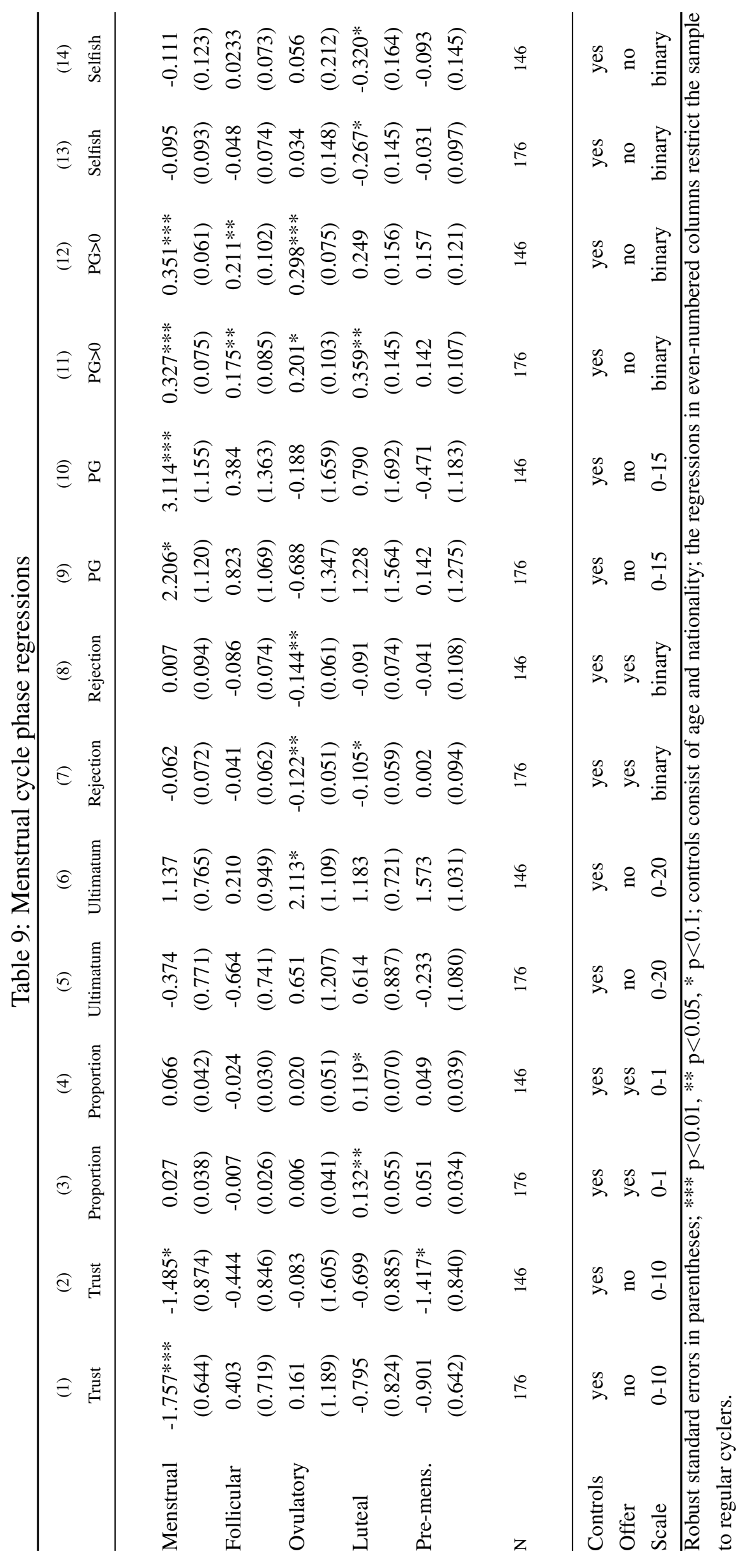




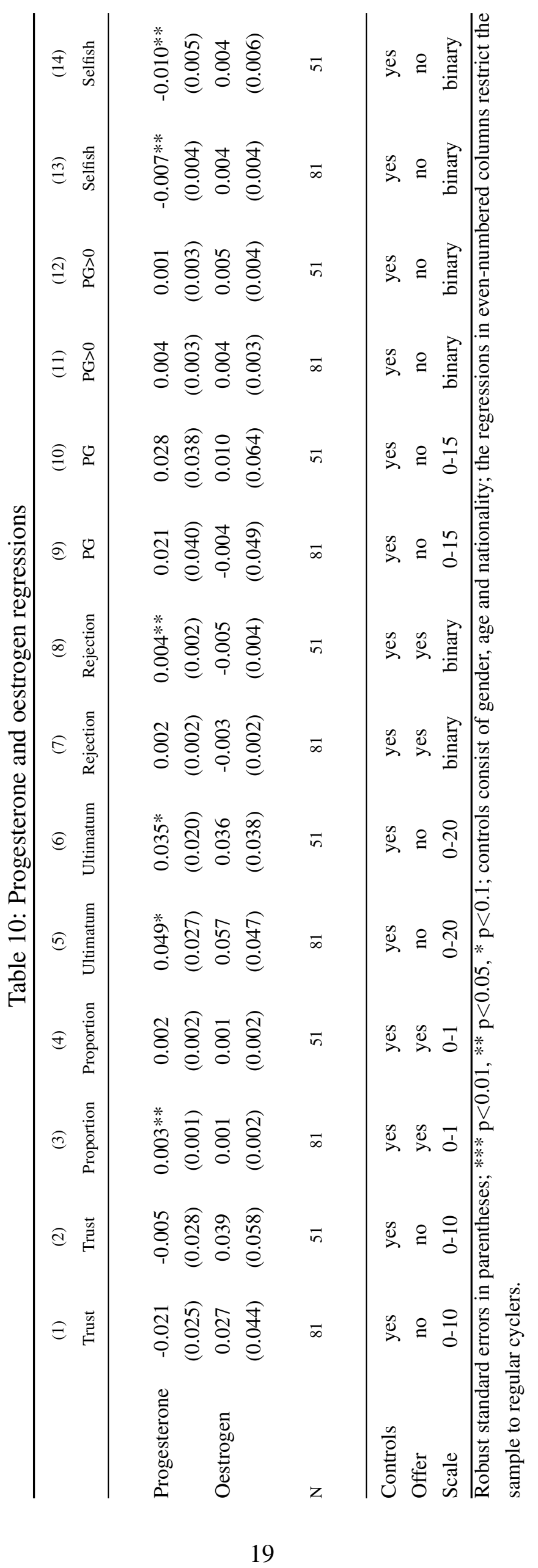




\section{References}

Altemus, Margaret, Catherine Roca, Elise Galliven, Catherine Romanos, and Patricia Deuster, "Increased Vasopressin and Adrenocorticotropin Responses to Stress in the Midluteal Phase of the Menstrual Cycle.," Journal of Clinical Endocrinology \& Metabolism, 2001, 86 (6), 2525-2530.

Apicella, Coren L., Anna Dreber, Benjamin Campbell, Peter B. Gray, Moshe Hoffman, and Anthony C. Little, "Testosterone and financial risk preferences," Evolution and Human Behavior, 2008, 29, 384-390.

Baron-Cohen, Simon, Svetlana Lutchmaya, and Rebecca Knickmeyer, Prenatal testosterone in mind, MIT Press, 2004.

Baumgartner, Thomas, Markus Heinrichs, Aline Vonlanthen, Urs Fischbacher, and Ernst Fehr, “Oxytocin Shapes the Neural Circuitry of Trust and Trust Adaptation in Humans.," Neuron, 2008, 58 (4), 639-650.

Berg, Joyce, John Dickhaut, and Kevin McCabe, “Trust, Reciprocity, and Social History," Games and Economic Behavior, 1995, 10 (1), 122-142.

Bröder, Arndt and Natalia Hohmann, "Variations in risk taking behavior over the menstrual cycle: An improved replication,” Evolution and Human Behavior, 2003, 24 (6), 391 - 398.

Brown, Windy M., Melissa Hines, Briony A. Fane, and S. Marc Breedlove, "Masculinized Finger Length Patterns in Human Males and Females with Congenital Adrenal Hyperplasia," Hormones and Behavior, 2002, 42 (4), 380 - 386.

Burnham, Terence C., "High-testosterone men reject low ultimatum game offers.," Proceedings of the Royal Society B: Biology, 2007, 274 (1623), 2327-2330.

Buser, Thomas, "Handedness predicts Social Preferences: Evidence connecting the Lab to the Field," Tinbergen Institute Discussion Papers 10-119/3, Tinbergen Institute November 2010.

_ , "The impact of the menstrual cycle and hormonal contraceptives on competitiveness," Journal of Economic Behavior \& Organization, 2011, forthcoming.

Cesarini, David, Christopher T. Dawes, James H. Fowler, Magnus Johannesson, Paul Lichtenstein, and Björn Wallace, "Heritability of cooperative behavior in the trust game," Proceedings of the National Academy of Sciences, 2008, 105 (10), 3721-3726.

_, _, Magnus Johannesson, Paul Lichtenstein, and Björn Wallace, "Genetic Variation in Preferences for Giving and Risk Taking," Quarterly Journal of Economics, 2009, 124 (2), 809-842.

Chabbert Buffet, N., C. Djakoure, S. Christin Maitre, and P. Bouchard, "Regulation of the Human Menstrual Cycle," Frontiers in Neuroendocrinology, 1998, 19 (3), 151-186. 
Chen, Yan, Peter Katuscak, and Emre Ozdenoren, "Why Can't a Woman Bid More Like a Man?," unpublished manuscript, 2009.

Coates, John M., Mark Gurnell, and Aldo Rustichini, "Second-to-fourth digit ratio predicts success among high-frequency financial traders," Proceedings of the National Academy of Sciences, 2009, 106 (2), 623-628.

Creinin, Mitchell D., Sharon Keverline, and Leslie A. Meyn, "How regular is regular? An analysis of menstrual cycle regularity," Contraception, 2004, 70 (4), 289 - 292.

Dreber, Anna and Moshe Hoffman, "Risk preferences are partly predetermined," Stockholm School of Economics, Mimeo, 2007.

Fischbacher, Urs, "z-Tree: Zurich toolbox for ready-made economic experiments," Experimental Economics, 2007, 10 (2), 171-178.

Grimshaw, Gina, M. Philip Bryden, and Jo-Anne Finegan, "Relations between prenatal testosterone and cerebral lateralization in children," Neuropsychology, 1995, 9 (1), 68 - 79.

Güth, Werner, Rolf Schmittberger, and Bernd Schwarze, "An experimental analysis of ultimatum bargaining," Journal of Economic Behavior \& Organization, 1982, 3 (4), 367-388.

Hampson, Elizabeth and Elizabeth A. Young, "Methodological issues in the study of hormonebehavior relations in humans: Understanding and monitoring the menstrual cycle," in Jill B. Becker, Karen J. Berkley, Nori Geary, Elizabeth Hampson, James P. Herman, and Elizabeth Young, eds., Sex differences in the brain. From genes to behavior., Oxford University Press, 2008, pp. 63-78.

Israel, Salomon, Elad Lerer, Idan Shalev, Florina Uzefovsky, Mathias Riebold, Efrat Laiba, Rachel Bachner-Melman, Anat Maril, Gary Bornstein, Ariel Knafo, and Richard P. Ebstein, "The Oxytocin Receptor (OXTR) Contributes to Prosocial Fund Allocations in the Dictator Game and the Social Value Orientations Task," PLoS ONE, 05 2009, 4, e5535.

Kahneman, Daniel, Jack L. Knetsch, and Richard H. Thaler, "Fairness and the Assumptions of Economics," The Journal of Business, 1986, 59 (4), S285-S300.

Knafo, Ariel, S. Israel, A. Darvasi, R. Bachner-Melman, F. Uzefovsky, L. Cohen, E. Feldman, E. Lerer, E. Laiba, Y. Raz, L. Nemanov, I. Gritsenko, C. Dina, G. Agam, B. Dean, G. Bornstein, and R. P. Ebstein, "Individual differences in allocation of funds in the dictator game associated with length of the arginine vasopressin 1a receptor RS3 promoter region and correlation between RS3 length and hippocampal mRNA," Genes, Brain and Behavior, 2008, 7 (3), 266-275.

Knickmeyer, Rebecca, Simon Baron-Cohen, Peter Raggatt, and Kevin Taylor, "Foetal testosterone, social relationships, and restricted interests in children," Journal of Child Psychology and Psychiatry, 2005, 46 (2), $198-210$. 
Kosfeld, Michael, Markus Heinrichs, Paul J. Zak, Urs Fischbacher, and Ernst Fehr, "Oxytocin increases trust in humans.," Nature, 2005, 435 (2), 673-676.

Ledyard, John, "Public Goods: A Survey of Experimental Research," in J. H. Kagel and Alvin E. Roth, eds., The Handbook of Experimental Economics, Princeton, NJ: Princeton University Press, 1995.

Levitt, Steven D. and John A. List, "What Do Laboratory Experiments Measuring Social Preferences Reveal about the Real World?," The Journal of Economic Perspectives, 2007, 21 (2), $153-$ 174.

Lutchmaya, Svetlana and Simon Baron-Cohen, "Human sex differences in social and non-social looking preferences, at 12 months of age," Infant Behavior and Development, 2002, 25 (3), 319 325.

_ , _ , Peter Raggatt, Rebecca Knickmeyer, and John T. Manning, "2nd to 4th digit ratios, fetal testosterone and estradiol," Early Human Development, 2004, 77 (1-2), 23 - 28.

Manning, J. T., R. L. Trivers, R. Thornhill, and D. Singh, "The 2nd:4th digit ratio and asymmetry of hand performance in Jamaican children," Laterality, 2000, 5, 121-132.

Manning, John T., Simon Baron-Cohen, Sally Wheelwright, and S. Sanders, "The 2nd to 4th digit ratio and autism," Developmental Medicine \& Child Neurology, 2001, 43 (3), 160-164.

Mansour, Diana, "Use of the new progestogens in contraception and gynaecology.," The Obstetrician \& Gynaecologist, 2006, (8), 229-234.

Miller, Geoffrey, Joshua M. Tybur, and Brent D. Jordan, "Ovulatory cycle effects on tip earnings by lap dancers: economic evidence for human estrus?," Evolution and Human Behavior, 2007, 28 (6), $375-381$.

Millet, Kobe and Siegfried Dewitte, "The presence of aggression cues inverts the relation between digit ratio (2D:4D) and prosocial behaviour in a dictator game," British Journal of Psychology, $2009,100,151-162$.

Pearson, Matthew and Burkhard C Schipper, "Menstrual cycle and competitive bidding," unpublished manuscript, 2009.

_ and _ , "The Visible Hand: Finger Ratio (2D:4D) and Competitive Behavior," Technical Report 16785, University Library of Munich, Germany 2009.

Penton-Voak, I. S., D. I. Perrett, D. L. Castles, T. Kobayashi, D. M. Burr, L. K. Murray, and R. Minamisawa, "Menstrual cycle alters face preference," Nature, 1999, (6738), 741-742. 
Richardson, John T.E., “The Menstrual Cycle, Cognition, and Paramenstrual Symptomatology,” in John T.E. Richardson, ed., Cognition and the Menstrual Cycle, Springer-Verlag, 1992.

Rivera, Roberto, Irene Yacobson, and David Grimes, "The mechanism of action of hormonal contraceptives and intrauterine contraceptive devices.," American Journal of Obstetrics \& Gynecology, 1999, 181, 1263-1269.

Robinson, S. J. and John T. Manning, "The ratio of 2nd to 4th digit length and male homosexuality," Evolution and Human Behavior, 2000, 21 (5), 333-345.

Rode, Catrin, Michael Wagner, and Onur Güntürkün, "Menstrual cycle affects functional cerebral asymmetries," Neuropsychologia, 1995, 33 (7), 855 - 865.

Roth, Alvin E., "Bargaining Experiments," in J. H. Kagel and Alvin E. Roth, eds., The Handbook of Experimental Economics, Princeton, NJ: Princeton University Press, 1995.

Salonia, Andrea, Rossella E. Nappib, Marina Pontilloc, Rita Daverioc, Antonella Smeraldid, Alberto Brigantia, Fabio Fabbria, Giuseppe Zannia, Patrizio Rigattia, and Francesco Montorsia, "Menstrual cycle-related changes in plasma oxytocin are relevant to normal sexual function in healthy women.," Hormones and Behavior, 2005, 47, 164-169.

Sanchez-Pages, Santiago and Enrique Turiegano, “Testosterone, Facial Symmetry and Cooperation in the Prisoners' Dilemma," Technical Report, Edinburgh School of Economics 2010.

Sapienza, Paola, Luigi Zingales, and Dario Maestripieri, "Gender differences in financial risk aversion and career choices are affected by testosterone," Proceedings of the National Academy of Sciences, 2009, 106 (36), 15268-15273.

Small, Chanley M., Amita K. Manatunga, and Michele Marcus, "Validity of Self-Reported Menstrual Cycle Length,” Annals of Epidemiology, 2007, 17 (3), 163 - 170.

Stern, Kathleen and Martha K. McClintock, "Regulation of ovulation by human pheromones," Nature, 1998, 1392 (6672), 177 - 179.

Thornhill, Randy and Steven W. Gangestad, "The Scent of Symmetry: A Human Sex Pheromone that Signals Fitness?," Evolution and Human Behavior, 1999, 20 (3), 175-201.

van Broekhoven, F., T. Bäckström, and R.J. Verkesa, "Oral progesterone decreases saccadic eye velocity and increases sedation in women.," Psychoneuroendocrinology, 2006, pp. 1190-1199.

van den Bergh, Bram and Siegfried Dewitte, "Digit ratio (2D:4D) moderates the impact of sexual cues on men's decisions in ultimatum games," Proceedings of the Royal Society B: Biological Sciences, 2006, 273 (1597), 2091-2095. 
Wallace, Björn, David Cesarini, Paul Lichtenstein, and Magnus Johannesson, "Heritability of ultimatum game responder behavior," Proceedings of the National Academy of Sciences, 2007, 104 (40), 15631-15634.

Witelson, Sandra F. and Richard S. Nowakowski, "Left out axoms make men right: A hypothesis for the origin of handedness and functional asymmetry," Neuropsychologia, 1991, 29 (4), 327 333.

Wozniak, David, William T. Harbaugh, and Ulrich Mayr, "Choices About Competition: Differences by gender and hormonal fluctuations, and the role of relative performance feedback," unpublished manuscript, 2010.

Zak, Paul J., Angela A. Stanton, and Sheila Ahmadi, “Oxytocin Increases Generosity in Humans.," PLoS One, 2007, 2 (11).

_ , Robert Kurzban, Sheila Ahmadi, Ronald S. Swerdloff, Jang Park, Levan Efremidze, Karen Redwine, Karla Morgan, and William Matzner, "Testosterone Administration Decreases Generosity in the Ultimatum Game.," PLoS One, 2009, 4 (12).

Zethraeus, Niklas, Ljiljana Kocoska-Maras, Tore Ellingsen, Bo von Schoultz, Angelica Linden Hirschberg, and Magnus Johannesson, "A randomized trial of the effect of estrogen and testosterone on economic behavior," Proceedings of the National Academy of Sciences, 2009, 106 (16), $6535-6538$. 